\title{
SISTEM INFORMASI BERBASIS WEB PADA TK ISLAM RABBANI JAKARTA SELATAN
}

\author{
Pandhu Pramarta \\ Program Studi Teknik Informatika, Universitas Indraprasta PGRI \\ pandhu.unindra@gmail.com
}

Submitted November 20, 2020; Revised November 25, 2020; Accepted December 4, 2020

\begin{abstract}
Abstrak
Dalam era sekarang ini dituntut untuk mengetahui dan mengerti perkembangan tentang pentingnya teknologi. Teknologi memberikan kemudahan dalam membantu kegiatan manusia khususnya di dunia akademik. Pada saat ini TK Islam Rabbani belum menggunakan website sebagai alat untuk media publikasi dan pertukaran informasi, sehingga informasi yang tersedia tidak dapat diakses oleh masyarakat luas secara real time. Dalam penelitian ini perancangan dan pembuatan web menggunakan Model SDLC (System Development Life Cycle) waterfall. Tujuan penelitian adalah perancangan dan pembuatan website untuk memudahkan akses informasi, sebagai sarana publikasi untuk dapat mencakup area yang lebih luas, dan meningkatkan awareness. Hasil dari penelitian ini adalah suatu website yang dapat membantu dan memudahkan guru, siswa dan semua pemangku kepentingan dari sekolah tersebut mudah untuk mendapatkan informasi secara cepat dan akurat. Mengacu hal tersebut maka diharapkan dengan penggunaan sistem informasi berbasis web, setiap informasi dapat diakses dan dipublikasikan kepada masyarakat luas, sehingga memudahkan masyarakat untuk mendapatkan informasi setiap saat melalui koneksi.
\end{abstract}

Kata Kunci : Teknologi, Informasi, Website, Internet.

\begin{abstract}
In this era, it is demanded to know and understand the development of the importance of technology. Technology provides convenience in helping human activities, especially in the academic world. At the moment Rabbani Islamic Kindergarten has not used the website as a tool for publication media and information exchange, so the information cannot be accessed by public in real time. In this research web is designed and created using SDLC (System Development Life Cycle) Waterfall Model. The research objective is designing and creating a website to facilitate easy access information, to cover wider area publication, and increase awareness. The results of this study are a website that helpful and easier for teachers, students and all stakeholders of the school to easily get information quickly and accurately. Referring to this, it is expected that by using a web-based information system, any information can be accessed and published to the people, making it easier for the public to get information at real time through an internet connection.
\end{abstract}

Key Words : Technology, Information, Website, Internet

\section{PENDAHULUAN}

Informasi adalah kombinasi antara prosedur kerja, informasi, orang dan teknologi informasi yang diorganisasikan untuk mencapai tujuan dalam sebuah organisasi [1] sedangkan sistem informasi merupakan suatu kumpulan dari komponen-komponen dalam organisasi yang berhubungan dengan proses penciptaan aliran informasi [2].

Perkembangan ilmu pengetahuan dijaman sekarang ini meningkat pesat. Manusia didorong untuk mengembangkan teknologi-teknologi baru untuk memenuhi kebutuhan informasi yang meningkat supaya pengolahan data dan informasi dapat dilakukan dengan cepat dan mudah. Untuk mempermudah semuanya tentu 
tidak hanya menggunakan tenaga manusia, akan tetapi menggunakan teknologi internet. Sudah bukan hal umun lagi bahwa sekarang sekolah-sekolah menikmati kemudahan mendapatkan informasi secara mudah dan cepat dengan menggunakan jaringan internet. Untuk itu, diperlukan sarana pendukung yaitu komputer dalam menyelesaikan suatu pekerjaan agar mempercepat dan mempermudah penyampaian informasi. Komputer dirasakan dapat menunjang kelancaran pekerjaan yang menuntut kecepatan, keterampilan, keakuratan, dan keefisienan waktu dan tenaga [3].

TK Islam Rabbani adalah sebuah sekolah taman kanak-kanak yang berada di wilayah Tanjung Barat, Jagakarsa, Jakarta Selatan. Saat ini TK Islam Rabbani telah memasang jaringan internet pada lingkungan sekolah namun manfaat jaringan internet ini belum maksimal.

Website atau situs dapat diartikan sebagai kumpulan halaman yang menampilkan informasi data teks, data diam atau gerak, data animasi, suara, video dan gabungan dari semuanya baik yang besifat statis maupun dinamis yang membentuk suatu rangkaian bangunan yang saling terkait dimana masing-masing dihubungkan dengan jaringan-jaringan halaman [4].

Mengingat website merupakan media yang sangat penting untuk menunjang kelancaran kegiatan belajar mengajar dan sebagai sarana promosi agar dapat menjangkau area yang lebih luas maka perlu dirancang sistem informasi berbasis web. Penerapan teknologi web application diperlukan agar komponen-komponen dapat terintegrasi dengan komponen digital [5].

Penelitian ini memiliki tujuan adalah merancang suatu website mengingat website merupakan media yang sangat penting untuk menunjang kelancaran kegiatan belajar mengajar dan sebagai sarana promosi agar dapat menjangkau area yang lebih luas. Perancangan merupakan proses pengembangan spesifikasi baru yang didasari oleh rekomendasi hasil analisis system [6].

Perancangan website ini menggunakan metode SDLC. SDLC atau Software Development Life Cycle atau sering disebut System Development Life Cycle adalah proses mengembangkan atau mengubah suatu sistem perangkat lunak dengan menggunakan model-model dan metodologi yang digunakan orang untuk mengembangkan sistem-sistem perangkat lunak sebelumnya (berdasarkan best practice atau cara-cara yang sudah teruji baik [7].

\section{METODE PENELITIAN}

Metode yang digunakan dalam pengembangan aplikasi atau sistem adalah model SDLC air terjun (waterfall) sering juga disebut model sekunsial linear atau alur hidup klasik (classic life cycle). Model air terjun menyediakan pendekatan alur hidup perangkat lunak secara sekuensial atau terurut dimulai dari analisis, desiain, pengodean, pengujian dan tahap pendukung (support).

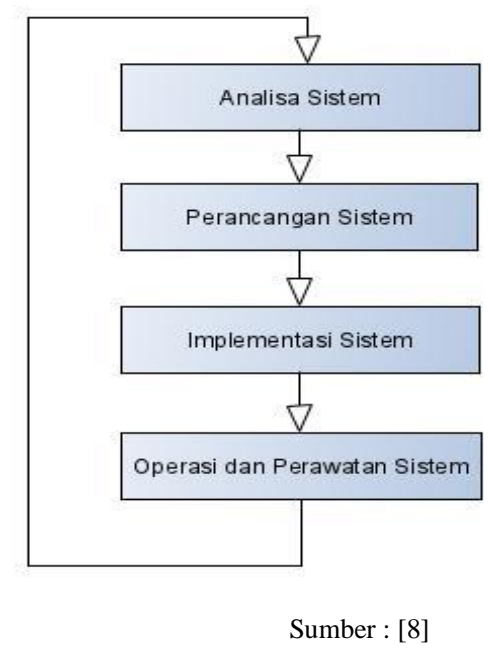

Gambar 1 : Siklus Hidup Pengembangan Sistem 
Tahap pertama dalam pengembangan sistem ini adalah analisa sistem yakni melihat kegiatan sistem yang sedang berjalan. Tahap ini menentukan mengenai potensi dan masalah yang ada yaitu sudah terpasang jaringan internet tetapi belum dimaksimalkan penggunaannya, terutama untuk pertukaran informasi yang selama ini dilakukan secara manual. Dengan dikembangkannya sistem informasi berbasis web akan mempermudah untuk pertukaran informasi dan sebagai sarana media pemasaran. Pada tahap analisa ini juga dilakukan langkah-langkah pengumpulan data. Pertama dengan melakukan observasi yaitu mengumpulkan data dengan melakukan pengamatan secara lansung terhadap objek penelitian dan kegiatan yang sedang berlangsung. Kedua melakukan wawancara yaitu dengan melakukan proses interaksi dan komunikasi atau tanya jawab pada pihakpihak terkait yang memberikan informasi tentang objek penelitian. Setelah itu yang ketiga melakukan dokumentasi dengan mengumpulkan sumber informasi berupa dokumen dan foto. Dan yang keempat yaitu melakukan studi pustaka untuk mengumpukan teori-teori dan buku-buku yang berkaitan dengan penelitian sebagai referensi.

Tahap kedua yakni desain produk. Pada tahap desain produk akan ditentukan program dan menentukan perancangan situs, sesuai spesifikasi dan kebutuhan. Merancang menu, mendesain modul, mendesain konten, merancang model alur sistem dengan diagram konteks dan DFD. Pengembangan basis data juga dilakukan pada tahap ini dengan menggunakan metode Database Life Cycle (DBLC). Alur hidup basis data dilakukan secara terurut dari mulai tahap analisis kebutuhan dan desain konseptual, desain lojik, desain fisik dan yang terakhir adalah implementasi.
Tahap ketiga adalah pengkodean yakni pembuatan kode program. Hasil dari tahap ini adalah program aplikasi sesuai dengan desain yang telah dibuat pada tahap desain.

Tahap keempat yakni pengujian. Pengujian dilakukan pada perangkat lunak dari segi lojik dan fungsional dan memastikan semua bagian sudah diuji. Hal ini dilakukan untuk meminimalkan kesalahan dan memastikan bahwa keluaran yang dihasilkan sesuai dengan yang diinginkan.

Selanjutnya adalah tahap kelima yakni pemeliharaan. Pada tahap ini mungkin dilakukan perubahan bila terdeteksi ada kesalahan pada saat aplikasi di implementasikan kedalam sistem. Tahap pemeliharaan dapat mengulangi proses pengembangan sistem dari mulai proses analisa tetapi tidak untuk membuat perangkat lunak baru.

\section{HASIL DAN PEMBAHASAN}

Data yang diperoleh dari tahap analisa dibuatkan rancangannya. Perancangan sistem ini merupakan hasil dari analisa kebutuhan dan spesifikasi yang dibuatkan diagram konteks dan data flow diagram.

DFD Level 0 disebut dengan diagram sistem inti (fundamental system diagram) atau model sistem inti (fundamental system model) atau biasa disebut juga diagram konteks (context diagram). Data Flow Diagram (DFD) atau dalam bahasa Indonesia menjadi Diagram Alir Data (DAD) adalah representasi grafik yang menggambarkan aliran informasi dan transformasi informasi yang diaplikasikan sebagai data yang mengalir dari masukan (input) dan keluaran (output) [7]. DFD dapat digunakan untuk menggambarkan sebuah sistem atau perangkat lunak pada beberapa level. DFD dapat dibagi menjadi beberapa level yang lebih detail untuk menggambarkan aliran informasi atau fungsi yang lebih detail.

DFD Level 0 menggambarkan sistem yang akan dibuat sebagai suatu entitas tunggal 
yang beriteraksi dengan orang maupun sistem lain. Pada DFD Level 0 ini terdapat sebuah sistem yaitu administrasi website dan dua external entity yaitu administrator dan pengguna. Berikut merupakan DFD Level 0 website TK Islam Rabbani.

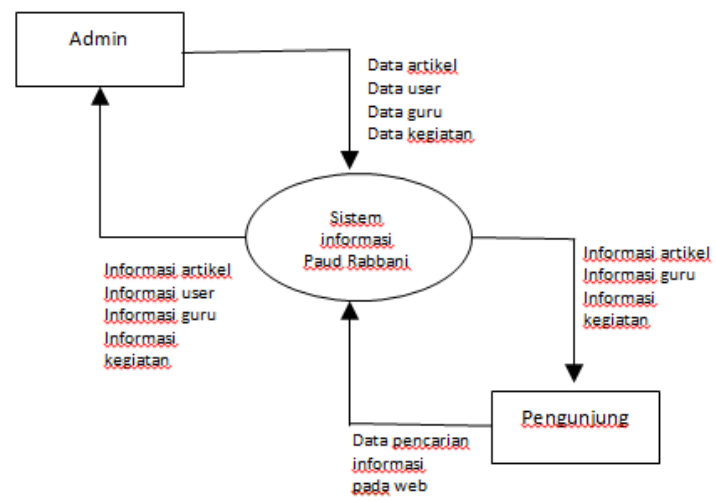

\section{Gambar 2. DFD Level 0}

DFD Level 1 digunakan untuk menggambarkan proses - proses yang ada dalam sistem yang akan dikembangkan. DFD Level 1 merupakan hasil breakdown DFD Level 0 yang sebelumnya telah dibuat. Berikut merupakan DFD Level 1 pada sistem informasi Paud Rabbani.

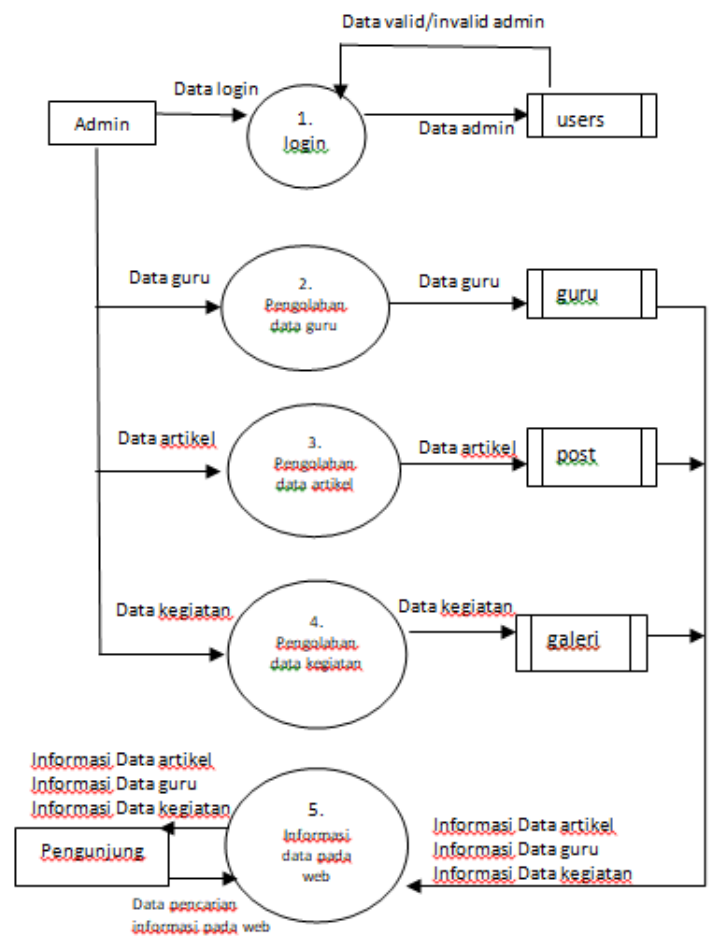

Gambar 3. DFD Level 1

\section{Halaman Utama}

Ketika pertama kali membuka website maka yang akan pertama kali tampil adalah halaman utama. Tampilan halaman utama dari website tersebut adalah sebagai berikut :

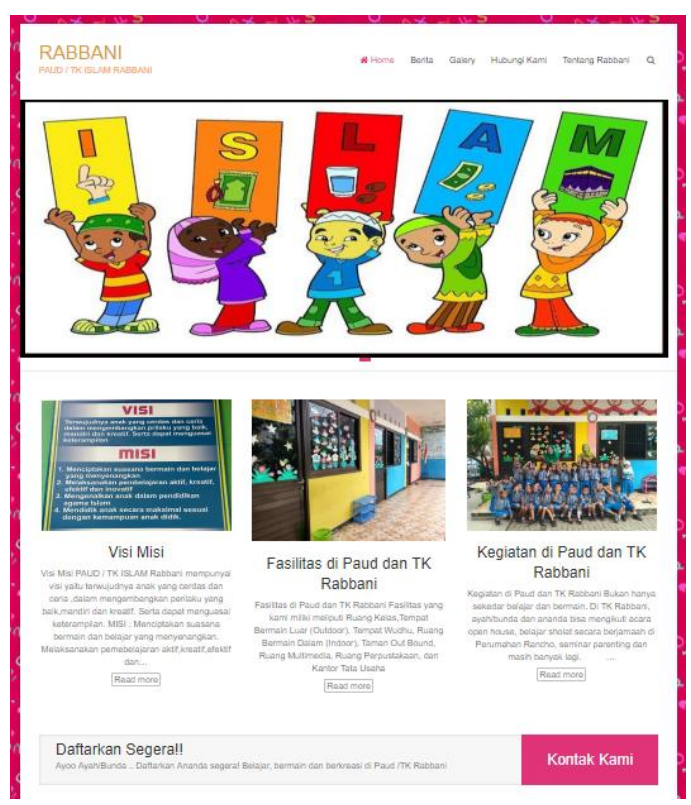

Gambar 4. Halaman Utama

\section{Halaman Artikel}

Pada halaman ini ditampilan artikel berisi tentang tulisan, berita dan artikel tentang pelajaran dan ilmu pengetahuan untuk mendapatkan informasi dan menambah wawasan pengunjung website PAUD Rabbani. 


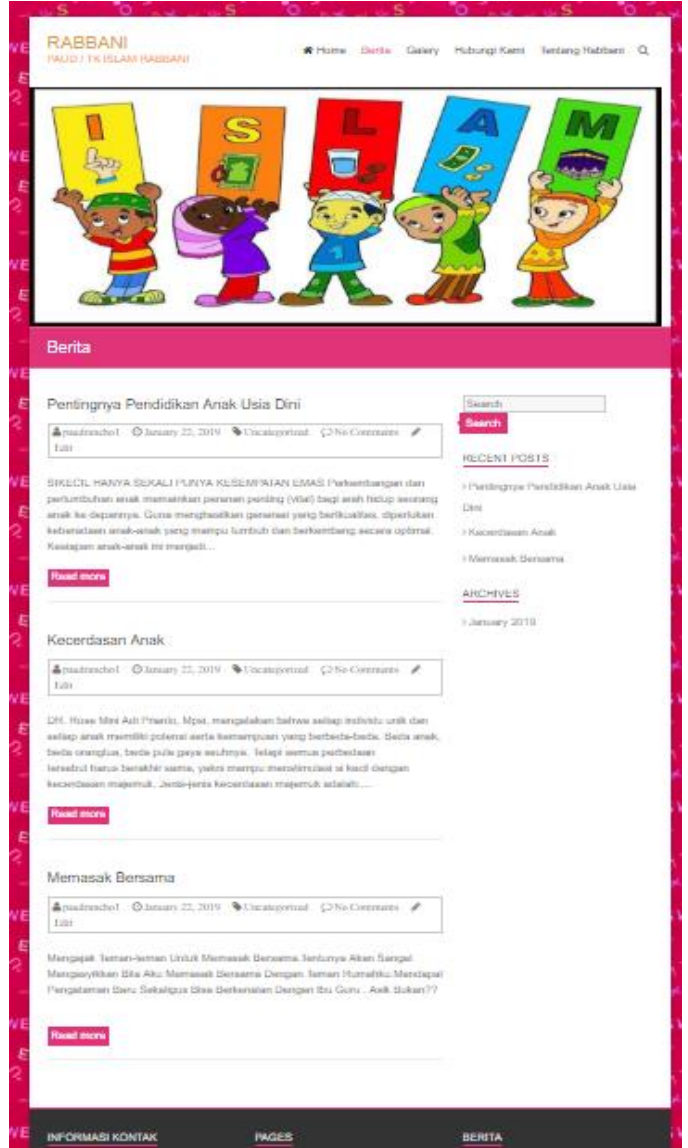

Gambar 5. Artikel

\section{Halaman Visi Misi}

Pada halaman ini berisi visi yaitu terwujudnya anak yang cerdas dan ceria ,dalam mengembangkan perilaku yang baik, mandiri dan kreatif. Serta dapat menguasai keterampilan. Misi yaitu menciptakan suasana bermain dan belajar yang menyenangkan. Melaksanakan pemebelajaran aktif, kreatif, efektif dan inovatif. Mengenalkan anak dalam pendidikan agama Islam. Mendidik anak secara maksimal sesuai dengan kemampuan anak didik.

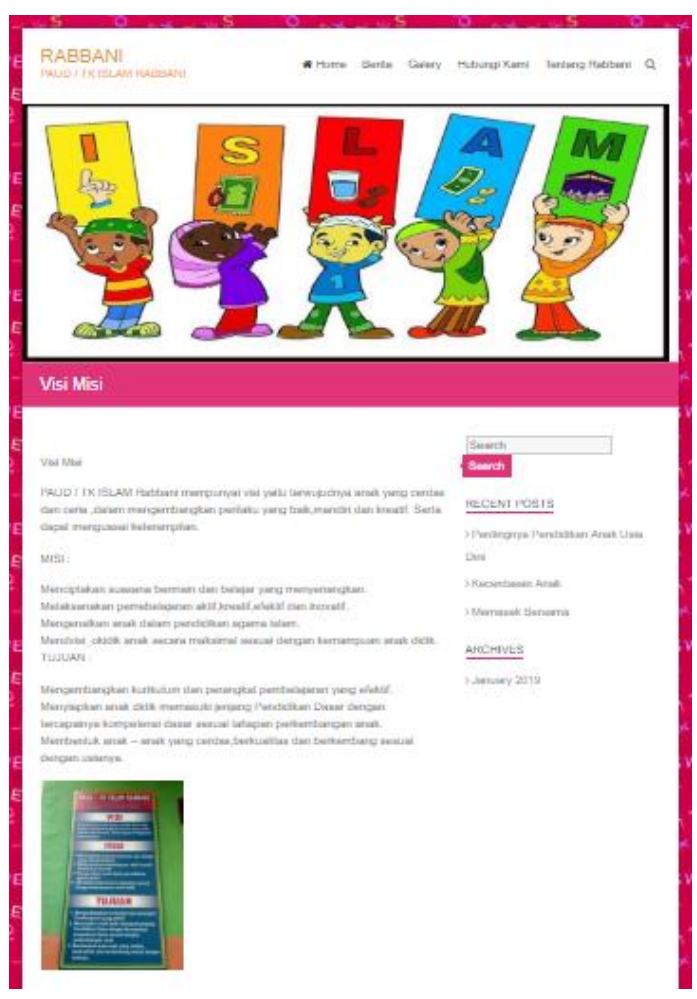

\section{Gambar 6. Visi Misi}

Setelah rancangan selesai dibuat dan website dapat berjalan sesuai dengan hasil rancangan terdapat maka sekolah ini sekarang dapat diakses dari mana saja dan secara realtime. Selama ini sekolah ini hanya diakses oleh masyarakat sekitarnya saja, sekarang dapat dijangkau secara luas Ini adalah manfaat dari dengan adanya sistem informasi berbasis web.

Webiste ini masih baru tahap awal dan jauh dari sempurna, saat ini hanya berisi halaman-halaman yang statis. Kedepan akan dapat dikembangkan dan diadakan perbaikan menjadi halaman yang dinamis dan interakti, serta diperlukan juga pengukuran untuk tingkat efisiensi dan efektifitas dan kepuasan pelanggan dalam menggunakan website ini.

\section{SIMPULAN}

Dari hasil penelitian yang telah dilakukan maka dapat disimpulkan bahwa: 
Permasalahan pada TK Islam Rabbani adalah terbatasnya akses kepada masyarakat yang ingin mengetahui dan membutuhkan informasi tentang TK Islam Rabbani. Dengan adanya penerapan penggunaan internet dan website, maka permasalahan mengenai akses informasi dapat tertangani. Selain mempermudah akses informasi, website ini juga digunakan sebagai sarana untuk publikasi, sehingga dapat mencakup area yang lebih luas dan meningkatkan awareness untuk TK Islam Rabbani.

\section{DAFTAR PUSTAKA}

[1] J. C. Wibawa and M. R. F., "Pengembangan Sistem Informasi Penjadwalan dan Manajemen Keuangan Kegiatan Seminar dan Sidang Skripsi/Tugas Akhir (Studi Kasus Program Studi Sistem Informasi UNIKOM)," J. Tek. Inform. dan Sist. Inf., vol. 3, no. 1, pp. 150-168, 2017, doi: 10.28932/jutisi.v3i1.585.

[2] A. Setiawan, "Sistem Informasi Penjadwalan Kunjungan Sales Dengan Berbasis Website Menggunakan SMS Gateway pada PT. Marco Motor," in
Prosiding Seminar Nasional Teknologi Informasi dan Komunikasi (SENATIK), 2019, vol. 2, no. 1, pp. 201-210.

[3] M. Haitami, I. Mutia, N.W. P. Septiani, Sistem Informasi Pengelolaan Rekam Medis Rumah Sakit Menggunakan Java, String, Vol 5 No 1, 2020.

[4] Christia, A, Sebri, Hesinto., Agustina. (2018). Rancang Bangun Website Sekolah Dengan Menggunakan Framework Bootstrap (Studi Kasus SMP Negeri 6 Prabumulih). Jurnal SISFOKOM, 7 (2)

[5] Irawan, Yudie. 2011. Tesis Perancangan Sistem Informasi Perpustakaan Berbasis Web Application. Semarang: Universitas Diponegoro.

[6] M. Subhan, Analisa Perancangan Sistem. Jakarta: Lentera Ilmu Cendikia, 2012.

[7] Rosa A.S dan Shalahuddin, M., Rekayasa Perangkat Lunak. Bandung: Informatika. 2018.

[8] Jogiyanto, Sistem Informasi Manajemen. Universitas Terbuka. 2017. 